University of Nebraska - Lincoln

DigitalCommons@University of Nebraska - Lincoln

Michigan Bovine Tuberculosis Bibliography and

Database

Wildlife Disease and Zoonotics

2006

\title{
Advances in Bovine Tuberculosis Diagnosis and Pathogenesis: What Policy Makers Need to Know
}

\author{
Mitchell V. Palmer \\ Bacterial Diseases of Livestock Research Unit, National Animal Disease Center, Agricultural Research \\ Service, USDA, Mitchell.Palmer@ars.usda.gov
}

W. Ray Waters

Follow this and additional works at: https://digitalcommons.unl.edu/michbovinetb

Part of the Veterinary Medicine Commons

Palmer, Mitchell V. and Waters, W. Ray, "Advances in Bovine Tuberculosis Diagnosis and Pathogenesis: What Policy Makers Need to Know" (2006). Michigan Bovine Tuberculosis Bibliography and Database. 69. https://digitalcommons.unl.edu/michbovinetb/69

This Article is brought to you for free and open access by the Wildlife Disease and Zoonotics at DigitalCommons@University of Nebraska - Lincoln. It has been accepted for inclusion in Michigan Bovine Tuberculosis Bibliography and Database by an authorized administrator of DigitalCommons@University of Nebraska Lincoln. 


\title{
Advances in bovine tuberculosis diagnosis and pathogenesis: What policy makers need to know
}

\author{
Mitchell V. Palmer*, W. Ray Waters \\ Bacterial Diseases of Livestock Research Unit, National Animal Disease Center, \\ Agricultural Research Service, USDA, 2300 Dayton Avenue, Ames, IA 50010, USA
}

\begin{abstract}
The mainstay of tuberculosis diagnosis in cattle and deer has been the tuberculin skin test. Recent advances have allowed the incorporation of blood based assays to the diagnostic arsenal for both cattle and deer. Use of defined and specific antigens has allowed for improved specificity of cell mediated assays in both cattle and deer and advances in antibody tests for tuberculosis have potential for use in free-ranging and captive cervid populations. Combined use of blood-based assays with skin testing will require further understanding of the effect of skin testing on the accuracy of blood based assays. Models of experimental infection of cattle have allowed for increased understanding of natural disease pathogenesis. Differences likely exist; however, between cattle and deer in both disease distribution and primary route of inoculation in naturally infected animals.

Published by Elsevier B.V.
\end{abstract}

Keywords: Cattle; Cervidae; Deer; Diagnosis; Mycobacteria; Mycobacterium bovis; Pathology; Tuberculosis

\section{Issues related to diagnosis-advances since the Mycobacterium bovis 2000 conference}

A workshop of the M. bovis 2000 conference on immunodiagnosis concluded that in vitro IFN- $\gamma$-based tests and improved antigens should be evaluated for use in TB eradication campaigns. At that time, antibody-based tests for cattle were lacking sensitivity, yet development of improved platforms and antigens was encouraged. It was acknowledged that antibody-

\footnotetext{
* Corresponding author. Tel.: +1 515663 7474; fax: +1 5156637458 .

E-mail address: mpalmer@nadc.ars.usda.gov (M.V. Palmer).
}

based tests are useful for diagnosis of tuberculous deer.

Since the last conference, the IFN- $\gamma$ assay has been widely adapted as a field test for bovine TB in multiple countries, either as a follow-up to or in parallel with tuberculin skin testing. Large scale field trials of the IFN- $\gamma$ assay in Australia in the early 1990's indicate that the sensitivity/specificity of the assay are 93.6/ 96.3\%, respectively (Wood et al., 1992). Additional studies indicate that the sensitivity of the assay ranges from 81.8 to $100 \%$ and the specificity from 94 to $100 \%$ (reviewed by Wood and Jones, 2001). In areas where TB prevalence is low, concern exists that the specificity of the IFN- $\gamma$ assay, using standard PPD antigens, is insufficient for program needs. 
For example, officials in Michigan, USA initiated IFN- $\gamma$ testing as a follow-up to tuberculin skin testing in 2004, with 2332 tests conducted during that year. Test performance is monitored separately in two zones within Michigan (i.e., locales based on TB prevalence). In 2004, test specificity was significantly greater in the TB endemic zone $(96.9 \%)$ compared to the TB disease-free zone $(\sim 90.8 \%)$ (Larry Judge, USDA, APHIS, personal communication). The unexpected lower specificity in the TB-free zone limits the use of the test in such areas due to higher than desired indemnity costs. To overcome this problem a validation study has been implemented in Michigan to evaluate the use of rESAT-6/CFP-10 for improving test specificity. Possibly, use of specific antigens will improve the specificity of the test and prove useful in areas of low TB prevalence.

Application of antibody-based tests has been extended to use with TB surveillance of free-ranging white-tailed deer in Michigan. Two advances have made this possible. First, a capture and release strategy in the TB endemic area was proven feasible. It was determined that a reasonable percentage of freeranging deer could be captured, bled, and radiocollared with minimal injuries. Secondly, antibodybased tests performed satisfactorily for TB surveillance of free-ranging white-tailed deer using blood samples collected by hunters. Antibody-based tests are particularly appealing for surveillance of captured free-ranging populations as test formats amenable to animal-side evaluation are now available. Additionally, serum can be stored for later analysis without need for immediate processing. This allows batch processing, application of confirmatory tests, option for allotment to multiple laboratories, and archiving for future tests. Antibody-based tests are also being evaluated for use in TB surveillance of free-ranging Eurasian badgers (Meles meles) in the UK and elk (Cervus elaphus nelsoni) in Canada. Similar applications may prove useful for other free-ranging populations (e.g., cape buffalo, lions, and elephants).

Application of skin testing and slaughter surveillance procedures has greatly reduced TB prevalence in countries with active eradication campaigns. Despite successes, new diagnostic challenges resulting from very low prevalence of disease and new wildlife reservoirs have resulted in the need for development and application of additional or improved tests. As vaccination schemes are implemented, tests to distinguish vaccinated from infected animals will also be required. The focus of this section on diagnosis is to highlight advances over the past 5 years and identify new applications for TB tests of cattle and wildlife.

\section{Host response}

The host response to the tubercle bacillus is complex and broad, involving all aspects of the immune system (Flynn and Chan, 2001; Kaufmann, 2001). The organism has evolved to avoid immune clearance and induce chronic lesions ensuring transmission by infectious aerosol droplets (North and Jung, 2004). Paradoxically, lesions (i.e., granulomas) are elicited as a mechanism to limit spread of the bacillus, thereby preventing early demise of the host. This complex host/pathogen interplay affords both diagnostic challenges and opportunities.

Robust delayed type hypersensitivity (DTH) and IFN- $\gamma$ responses are elicited upon experimental and natural infection with $M$. bovis. The bias of the immune response to $M$. bovis is a T helper type- 1 response as evidenced by IFN- $\gamma$, interleukin (IL)-12, and tumor necrosis factor (TNF)- $\alpha$ production to pathogen-associated antigen and exacerbation of disease when these cytokine pathways are disrupted (e.g., genetic deficiencies or inhibitory therapies) (Flynn, 2004). Thus, a mainstay for TB diagnosis is evaluation of these cell-mediated responses either by skin test (Monaghan et al., 1994) or IFN- $\gamma$-based assays (Wood and Jones, 2001). Mycobacterial infections also induce antibody responses. In general, specific antibody responses are most easily detected late in disease and correlate with severe progression of disease (Plackett et al., 1989). With improving technologies, the current dogma of early cell-mediated and late humoral responses to mycobacterial infections may be challenged (Koets et al., 2001). Indeed, intratonsilar inoculation of cattle with Mycobacterium avium subsp. avium, M. avium subsp. paratuberculosis, Mycobacterium kansasii, or M. bovis induces an antibody response detectable within 2-4 months of inoculation; however, the intratonsilar route may favor early antigen/B cell interactions facilitating production of specific antibody (Waters et al., 2003, 2004a; Waters et al., Unpublished observations). 


\section{Complex versus specific antigens}

Over the past century, the predominant antigens used for TB diagnosis have been complex, ill-defined whole cell lysates and culture filtrates, particularly tuberculin. Complex preparations provide a wide array of antigens for presentation to lymphocytes and are representative of the range of antigens presented to the host upon infection. The most widely used antigen for diagnosis of tuberculous cattle is purified protein derivative (PPD) prepared from heat-killed cultures of mycobacteria. PPD provides excellent sensitivity for diagnostic tests yet lacks specificity due to epitopes shared by various mycobacteria and other closely related bacteria. Either in vivo (skin test) or in vitro (IFN- $\gamma$ ) comparisons made between responses to $M$. bovis derived PPD and M. avium derived PPD are beneficial for differentially diagnosing responses to the respective mycobacteria. Improved specificity may be obtained through use of defined antigens. Of particular relevance for cattle are antigens that can be used to distinguish between $M$. bovis and $M$. avium infection. Other mycobacterial species commonly isolated from cattle within the USA include: Mycobacterium kansasii, Mycobacterium fortuitum, Mycobacterium smegmatis, Mycobacterium pulveris, Mycobacterium gadium, Mycobacterium terrae complex, and Mycobacterium duvalii (Beth Harris, personal communication). Responses generated by exposure to non-tuberculous mycobacteria and other related non-mycobacterial species might be of greater significance for diagnostic tests used with cervids. A prime example is reindeer (Rangifer tarandus) that are notably prone to cross reactive responses that interfere with TB test interpretation using standard PPD antigens.

ESAT- 6 and CFP-10 are potent IFN- $\gamma$-inducing antigens of tuberculous mycobacteria. These two proteins are co-secreted and form a tight 1:1 complex upon export (Renshaw et al., 2002). Genes for ESAT-6 and CFP-10 are absent in many environmental, nontuberculous mycobacteria as well as in the TB vaccine strain, M. bovis BCG. Use of ESAT-6 and/or CFP-10 as antigens in IFN- $\gamma$-based TB assays enhances specificity when compared to use of $M$. bovis PPD (Pollock and Andersen, 1997; Pollock et al., 2000; Vordermeier et al., 2001; Buddle et al., 2001, 2003). Unfortunately, genes for EAST-6 and CFP-10 are present in some non-tuberculous mycobacteria, most notably M. kansasii, M. marinum, M. leprae, and $M$. smegmatis (Gey Van Pittius et al., 2001, 2002; Geluk et al., 2002, 2004). Experimental infection of cattle with $M$. bovis, $M$. avium subsp. avium, M. avium subsp. paratuberculosis, or M. kansasii has demonstrated that a fusion protein of ESAT- 6 and CFP-10 is recognized by $M$. bovis and $M$. kansasii-infected cattle but not by cattle infected with either of the two $M$. avium strains (Waters et al., 2004a; Waters et al., Unpublished observations). ESAT-6 has also been used to discriminate between cattle naturally infected with $M$. bovis and cattle sensitized/infected with environmental, non-tuberculous strains of mycobacteria or vaccinated for paratuberculosis (Pollock and Andersen, 1997; Buddle et al., 2003). In Ireland studies have demonstrated the potential for ESAT- 6 as a skin test antigen; however, large quantities of antigen (up to $400 \mu \mathrm{g}$ ) and extended time to reading (i.e., 5 days instead of 3 days for standard antigens) are required for best results (Pollock et al., 2003). It should be noted that these potential pitfalls might be overcome with use of adjuvants or additional specific antigens.

A relatively large number of $M$. tuberculosis complex-specific antigens were discovered and characterized in the late 1990s. Clearly, ESAT-6 and CFP-10 are leading candidates for improved antigens for use with cellular-based assays. Recently, Vordermeier et al. (2004) demonstrated that use of a fusion protein of ESAT-6, CFP10, and detoxified Bordetella pertussis adenylate cyclase improves the frequency of responding cells in an IFN- $\gamma$ assay. Other antigens such as Ag85, MPB83, MPB64, MPB70, Phos1 (38 $\mathrm{kDa}$ antigen), and somatic stress proteins have been evaluated for use in cellular based assays with variable success (Fifis et al., 1994; Vordermeier et al., 1999; Rhodes et al., 2000; Pollock et al., 2001; Buddle et al., 2003). Recent advances in whole genome sequencing of M. bovis (Garnier et al., 2003) and related mycobacteria (e.g., M. avium subsp. avium and M. avium subsp. paratuberculosis) have resulted in identification of numerous additional putative antigenic targets. Use of antigen cocktails and fusion proteins may be employed to enhance the sensitivity of specific antigen based tests. For instance, Lyashchenko et al. (2000) developed an antibody-based test using complex and defined antigens. This test (multi- 
antigen print immunoassay or MAPIA) is useful for screening responses by various host species to determine antigen recognition patterns and kinetics of responses to various antigens during the course of infection and even in response to antibiotic therapy. Optimal antigens as defined by MAPIA are then used in a lateral flow immunoassay format or "Rapid Test" (Greenwald et al., 2003). The Rapid Test is easy to use, amenable to animal side testing, adaptable for multispecies use, and results are obtained within $15 \mathrm{~min}$. This strategy has proven promising for use in various species including white-tailed deer, Eurasian badgers, cattle, and various zoo species (Greenwald et al., 2003; Lyashchenko et al., 2004; Waters et al., 2004b; Lyashchenko, personal communication). As with MAPIA and Rapid Test, future diagnostics including cell- and antibody-based tests will likely employ the use of complex antigens for test sensitivity and defined antigens for test specificity.

\section{Effects of skin test on cell- and antibody- based assays}

Injection of PPD for skin testing elicits a temporary suppression of in vivo responsiveness to mycobacterial antigens that may confound interpretation of subsequent tests (Lepper et al., 1977; Radunz and Lepper, 1985; Thom et al., 2004). Such suppression is present from 4 to 60 days after injection (Radunz and Lepper, 1985; Doherty et al., 1995). Mechanisms underlying this reduced responsiveness are unclear; however, both cellular and humoral factors have been proposed. Practically, this phenomenon limits the versatility of skin testing and is a forewarning of the impact of antigen administration on subsequent in vitro-based testing.

As with DTH responses, lymphocyte proliferative responses are suppressed immediately following injection of PPD in M. bovis-infected or sensitized cattle (Doherty et al., 1995; Hall and Thoen, 1983). In contrast, antibody responses are enhanced by PPD injection, with peak effects 2 weeks after injection (Lyashchenko et al., 2004). Effects of skin testing on the $M$. bovis-specific IFN- $\gamma$ response, however, remain unclear. Most studies indicate that IFN- $\gamma$ responses are either not affected or slightly boosted immediately after skin testing (i.e., 7-28 days later)
(Buddle et al., 1995; Doherty et al., 1995; Rothel et al., 1992; Gormley et al., 2004). Ryan et al. (2000) determined that the IFN- $\gamma$ test is reliable when applied 8-28 days after skin testing; however, responses at these time points were not compared to pre-skin test responses. Rothel et al. (1992) found a marked decline in the IFN- $\gamma$ response to $M$. bovis PPD at 7 days after skin test; however, this decline was followed by an enhanced response. Using $M$. bovis sensitized cattle, Whipple et al. (2001) found that PPD specific IFN- $\gamma$ responses were boosted 7 days after skin test. Injection of M. bovis PPD for the caudal fold test in 19 experimentally infected calves resulted in slightly boosted IFN- $\gamma$ responses 3-5 days after injection and responses from 7 to 55 days later that were similar to pre-skin test values (Palmer et al., Unpublished observations).

\section{Issues related to pathogenesis}

The pathogenesis of bovine tuberculosis is not as well understood as the pathogenesis of tuberculosis in humans. Advances in the field of human tuberculosis have been made using various small animal models of M. tuberculosis infection. Extrapolations of findings from small animal models have been made to bovine tuberculosis. Such extrapolations may not always be appropriate as there are profound differences in host susceptibility, host immune response, environment, host ecology, and behavior. The current discussion will deal primarily with studies in cattle and cervids.

\section{Route of infection and lesion distribution}

With some exceptions, it is agreed that cattle become infected with $M$. bovis by either the oral or respiratory routes (Neill et al., 1994). The oral route is likely most important in calves nursing tuberculous cows, while the respiratory route is most common in cattle in general (Neill et al., 1994). In the late 1990's, surveys of tuberculous cattle in Great Britain (Phillips et al., 2003) revealed that $67 \%$ of tuberculous lesions were within the lungs and pulmonary lymph nodes (tracheobronchial and mediastinal). Cranial lymph node lesions were observed in 39\%, while only $8 \%$ of lesions involved mesenteric lymph nodes. Although 
many studies demonstrate a tendency toward lesion development in pulmonary lymph nodes rather than in lungs, meticulous examination often reveals lesions in the lungs; most $<1 \mathrm{~cm}$ in diameter (Mcllroy et al., 1986). Indeed, most studies of naturally infected cattle describe the majority of lesions within the lung, pulmonary lymph nodes and cranial lymph nodes (Stamp, 1944; Lepper and Pearson, 1973). The conclusion is that this distribution of lesions suggests a respiratory route of infection. Investigations in naturally infected cattle suggest that lesions of the alimentary tract, although not common generally, are more common in temperate climates where conditions favor dissemination and survival of $M$. bovis on forage, while respiratory tract lesions are more common in arid climates where conditions favor aerosolization of $M$. bovis (Lepper and Pearson, 1973).

In white-tailed deer and other cervids, lesion distribution differs from that seen in cattle. In whitetailed deer, elk (Cervus elaphus nelsoni), and red deer (Cervus elaphus) the preponderance of lesions occur in the medial retropharyngeal lymph nodes (Beatson, 1985; Whiting and Tessaro, 1994; O'Brien et al., 2001; Palmer et al., 2000). Similar to M. bovis infection of humans, but unlike tuberculosis in cattle, discharging sinus tracts have been associated with cranial lymph node lesions in red deer (Mackintosh and Griffin, 1994) and fallow deer (Dama dama) (Robinson et al., 1989), but not white-tailed deer. Tonsilar lesions are commonly seen in white-tailed deer with tuberculous lesions of the medial retropharyngeal lymph nodes (Palmer et al., 2002b). In ruminants, afferent lymphatics are not present in the tonsil while efferent lymphatics drain from the tonsil directly to the retropharyngeal lymph nodes. This primary complex of tuberculous lesions involving the tonsil and retropharyngeal lymph nodes is remarkably similar to that seen in humans. Indeed, in humans the primary complex resulting from oral exposure to $M$. bovis through consumption of unpasteurized milk consists of lesions in the tonsil and draining lymph node (Ramsay, 1992; Samuelson and von Lichtenberg, 1994). This has led to the hypothesis that white-tailed deer are generally infected with $M$. bovis through the oral route. Supporting evidence exists in demonstrations of deer to deer transmission through sharing of feed (Palmer et al., 2004b).
In white-tailed deer, as well as other cervids, routes of inoculation that mimic oral exposure may be more relevant models of natural infection than those simulating aerosol exposure. Models of natural infection in red deer and white-tailed deer (Mackintosh et al., 1995; Palmer et al., 1999a) using intratonsilar inoculation result in lesion distribution similar to that seen in naturally infected deer (O'Brien et al., 2001). Moreover, aerosol exposure of whitetailed deer to $M$. bovis did not result in lesion distribution similar to that seen in most naturally infected deer (Palmer et al., 2003).

It has been stated that the route of transmission of $M$. bovis can be deduced by the pattern of lesions observed in the infected animal (Biet et al., 2005). However, such a determination may not be straightforward. A recent study in cattle showed that feeding various doses of $M$. bovis resulted in lesions limited to the lung, pulmonary lymph nodes and cranial lymph nodes with no involvement of mesenteric lymph nodes or abdominal viscera (Palmer et al., 2004a). Furthermore, $M$. bovis could not be isolated from mesenteric lymph nodes or abdominal viscera by bacteriological culture. In this same study, interspecies transmission of $M$. bovis by sharing of feed between cattle and deer did not result in lesions of the mesenteric lymph nodes or abdominal viscera, but rather lesions of the lung, pulmonary lymph nodes and cranial lymph nodes.

Critical to assessment of route of infection through lesion distribution is the understanding of the primary complex. The primary complex of tuberculosis is considered to be the combination of lesions in the initial focus of infection and the regional (i.e. draining) lymph node. In cases of prolonged or severe disseminated disease, determination of the primary complex may be impossible, confusing speculation concerning the initial route of infection. Moreover, when infection occurs across mucous membranes such as the pharynx or intestine, the initial lesion in the mucous membrane may not be visible while lymph node lesions are obvious (Dungworth, 1993).

\section{Minimum infectious dose}

The dose of M. bovis that cattle and deer are exposed to in nature is unknown, but is likely highly variable and repeated. The minimum infectious dose is 
highly dependent on the route of infection. In numerous studies in guinea pigs reviewed by Sigurdson (1945) infection through the oral route required doses orders of magnitude greater than that required for infection via aerosol. In fact, doses as low as 1-5 bacilli resulted in infection via aerosol, while 10-20 million bacilli were required to infect via the oral route.

There is great variation in the reported minimum infectious dose for cattle. Variations are due to differences in individual animals, host species, bacterial strain and route of inoculation. Studies reviewed by Francis (1947) showed that doses of $10^{6}$ $10^{7} \mathrm{CFU}$ were required to infect cattle or sheep through the oral route, while as few as $1-5$ bacilli could infect via the aerosol route. Studies in cattle cited by Griffin and Dolan (1995) report that $4 \times 10^{5}$ bacilli are required for infection via the respiratory route and 1000 times more bacilli are required for infection through the oral route. Recent investigations; however, have shown that cattle can be infected orally with as few as $5000 \mathrm{CFU}$ of $M$. bovis administered in the feed (Palmer et al., 2004a). Conversely, mathematical modeling of $M$. bovis excretion by tuberculous cattle suggests that a single bacillus may be sufficient to cause infection by the aerosol route (Neill et al., 1991).

\section{Natural versus experimental infection}

To simulate natural disease, experimental infection of cattle with $M$. bovis has been done by intranasal (Cassidy et al., 1998, 1999), intratracheal (Buddle et al., 1994) and intratonsilar routes (Palmer et al., 1999b). Infections via the respiratory route in cattle likely mimic natural infection more than other methods of inoculation. However, there are various means by which inoculum may be introduced into the respiratory tract (e.g. intranasal, intratracheal, aerosol). Intranasal administration of $10^{4}-10^{5} \mathrm{CFU}$ of $M$. bovis reliably results in lesions in the lungs and pulmonary lymph nodes. However, many other organs are also involved suggesting development of generalized tuberculosis (Neill et al., 1988b). Moreover, lesions are also commonly noted in the nasopharyngeal mucosa and trachea; sites not commonly affected in naturally infected cattle. Intranasal doses of
$10^{3}-10^{5}$ CFU have been suggested to be too high to simulate natural infection, resulting in atypical lesions in the upper respiratory tract and exaggerated involvement of the lungs (Phillips et al., 2003). Intranasal administration of $92 \mathrm{CFU}$ of $M$. bovis did not result in lesion formation (Neill et al., 1988b).

Intratracheal inoculation of 500-800 CFU of $M$. bovis results in lesions limited to the lungs and pulmonary lymph nodes (Buddle et al., 1994 and 1995). Inoculation using higher doses (e.g., $5 \times 10^{5}$ $\mathrm{CFU}$ ) results in widespread lesions suggestive of generalized tuberculosis. Tracheal lesions, uncommon in natural infection, can also result as an artifact of the inoculation method.

Intratonsilar inoculation of cattle with $1 \times 10^{5}$ CFU of $M$. bovis results in consistent early lesion formation in the medial retropharyngeal lymph nodes (Palmer et al., 1999b) and later lesion development in the lung and pulmonary lymph nodes (Palmer, Unpublished results). Higher doses result in lesions of generalized tuberculosis.

In aerosol exposure, the size of aerosolized droplets carrying $M$. bovis is as important as the dose of inoculum. The droplet nuclei mechanism of $M$. tuberculosis infection in humans has shown that residues, $<5 \mu \mathrm{m}$, of evaporated droplets (droplet nuclei) can be generated by talking or coughing. Droplet nuclei remain airborne for prolonged periods while larger droplets settle within short distances of their source. Once inhaled, infectious droplet nuclei reach the terminal bronchioles and alveoli, while droplets $>5 \mu \mathrm{m}$ are removed in the upper respiratory passages (Wells et al., 1948; Loudon and Roberts, 1967, 1968). Recent studies in cattle using aerosols containing $M$. bovis generated by a nebulizer have shown that nebulization of $1000 \mathrm{CFU}$ of M. bovis can result in lesions similar to those seen in natural infection (Palmer et al., 2002a). Lesions are limited to the lungs and pulmonary lymph nodes with no lesions in cranial lymph nodes, nasopharyngeal mucosa, or trachea. Moreover, M. bovis could only be isolated by bacteriological culture from the lungs and pulmonary lymph nodes when doses of $1000 \mathrm{CFU}$ were nebulized.

Direct and indirect contact exposure has been successfully used to experimentally inoculate cattle and deer. In many cases transmission rates have been less than $100 \%$ with not all in-contact animals developing tuberculosis (Neill et al., 1989; Palmer 
et al., 2004a), suggesting that the dose, although difficult to control, is not overwhelming. Moreover, the resulting distribution of lesions closely resembles that seen in nature in both cattle and deer. White-tailed deer, whether exposed to $M$. bovis directly through shared housing (Palmer et al., 2001) or indirectly through shared feed (Palmer et al., 2004b), develop lesions similar to those seen in naturally infected deer (O'Brien et al., 2001). The lack of dosage control; however, limits the utility of such a model in situations such as vaccine efficacy studies, where the assurance of a standardized dosage is critical.

\section{Shedding}

In most countries with active bovine tuberculosis control programs, infected herds contain few infected animals. Currently, it is uncommon to find large numbers of infected animals within a herd. This is due in part to regular herd monitoring through skin testing. The occurrence of low numbers of infected animals within herds has also led to the belief that bovine tuberculosis is characterized by low cattle to cattle transmissibility with low numbers of $M$. bovis bacilli shed by infected animals and a large infectious dose required to initiate new infection in naïve animals. Accurate quantitative assessments of shedding of $M$. bovis from infected cattle are difficult. In humans, repeated sputum samples are evaluated before a diagnosis is reached. In cattle, most investigations have involved single time-point samples. In some cases, $M$. bovis infection has been confirmed by detailed postmortem examination, including bacteriologic culture (McIlroy et al., 1986), in others, however, no such examination was conducted (De Kantor and Roswurm, 1978). Estimates from such studies suggest that 9-19\% of infected cattle shed $M$. bovis in nasal or tracheal secretions.

Experimental studies to examine shedding document latent periods between inoculation and initiation of shedding. This latent period appears to be inversely related to inoculum size. Cattle receiving $10^{4} \mathrm{CFU}$ of $M$. bovis intranasally shed $M$. bovis in nasal mucus in 17.6 days, while cattle receiving $10^{6} \mathrm{CFU}$ intranasally shed $M$. bovis in nasal mucus in 11 days (Neill et al., 1988a). Once initiated, shedding is intermittent for up to 38 weeks.
Many investigators have categorized tuberculosis in cattle as either open or closed. Open cases of tuberculosis are those in which lesions, primarily in the lung, allow excretion of M. bovis, while closed cases are categorized by lesions that do not promote excretion of bacilli. It is artificial to categorize cases as open or closed, as many cases do not present with obvious gross pulmonary lesions, yet contain small lesions that are only detectable after meticulous examination, including microscopic examination. Careful examination revealed that $73 \%$ of bovine cases with pulmonary lymph node lesions also had lesions in the lungs (McIlroy et al., 1986). In 63\% of the cases only one lung lesion was present and $70 \%$ of the lung lesions were $<1 \mathrm{~cm}$ in diameter. The authors conclude that all tuberculous cattle with lesions in the pulmonary lymph nodes should be considered capable of excretion of $M$. bovis. In a separate study of tuberculin positive cattle, although all had gross lesions of the pulmonary lymph nodes, only one animal had gross lung lesions. M. bovis was found by bacteriological culture; however, in 4 of the 25 animals, demonstrating that gross lung lesions are not a prerequisite of bacillary shedding (Neill et al., 1988a). Moreover, animals with no visible lesions are not necessarily non-infected. M. bovis has been isolated from skin-test negative animals with no gross lesions (Neill et al., 1992). Meanwhile, as many as $10 \%$ of cattle with no visible lesions can be culture positive for M. bovis (Corner, 1994).

\section{Host species differences}

Species differences in susceptibility to infection with $M$. bovis are known to exist. Differences in lesion distribution between cattle and cervids have been discussed. However, differences among species of Cervidae also exist. The most accurate comparisons are made by inoculation of different species by similar routes using similar dosages. Such a side by side comparison has demonstrated that white-tailed deer develop more widespread lesions than reindeer when dosed intratonsilarly with $10^{5} \mathrm{CFU}$ of $M$. bovis (Palmer et al., 2006). Intratonsilar inoculation of red deer with similar doses of $M$. bovis results in infection in $90 \%$ and lesions in $70 \%$ of inoculated animals (Griffin and Mackintosh, 2000). This suggests that 
reindeer are similar to red deer in their susceptibility and response to experimental infection with $M$. bovis and that white-tailed deer may be more susceptible to $M$. bovis than other species of deer.

\section{Conclusion}

Future research will likely focus on improving the sensitivity and specificity of both cell-mediated and humoral blood based assays for bovine tuberculosis. The increasing importance of wildlife in the epidemiology of bovine tuberculosis will require continued research on diagnosis and pathogenesis of $M$. bovis infection in the various wildlife species. There are still many unsolved problems associated with the pathogenesis and immune response to tuberculosis. The variation of responses in a variety of susceptible hosts makes the problem especially challenging. A broad, multi-disciplinary approach in comparative pathology, comparative immunology and molecular biology will be required.

\section{References}

Beatson, N.S., 1985. Tuberculosis in red deer in New Zealand. In Biology of deer production. R. Soc. N.Z. Bull. 22, 147-150.

Biet, F., Boschiroli, M.L., Thorel, M.F., Guilloteau, L.A., 2005. Zoonotic aspects of Mycobacterium bovis and Mycobacterium avium-intracellulare complex (MAC). Vet. Res. 36, 411-436.

Buddle, B.M., Aldwell, F.E., Pfeffer, A., de Lisle, G.W., Corner, L.A., 1994. Experimental Mycobacterium bovis infection of cattle: effect of dose of $M$. bovis and pregnancy on immune responses and distribution of lesions. N.Z. Vet. J. 42, 167-172.

Buddle, B.M., de Lisle, G.W., Pfeffer, A., Aldwell, F.E., 1995. Immunological responses and protection against Mycobacterium bovis in calves vaccinated with a low dose of BCG. Vaccine 13, 1123-1130.

Buddle, B.M., McCarthy, A.R., Ryan, T.J., Pollock, J.M., Vordermeier, H.M., Hewinson, R.G., Andersen, P., de Lisle, G.W., 2003. Use of mycobacterial peptides and recombinant proteins for the diagnosis of bovine tuberculosis in skin test-positive cattle. Vet. Rec. 153, 615-620.

Buddle, B.M., Ryan, T.J., Pollock, J.M., Andersen, P., de Lisle, G.W., 2001. Use of ESAT-6 in the interferon-gamma test for diagnosis of bovine tuberculosis following skin testing. Vet. Microbiol. 80, 37-46.

Cassidy, J.P., Bryson, D.G., Pollock, J.M., Evans, R.T., Forster, F., Neill, S.D., 1998. Early lesion formation in cattle experimentally infected with Mycobacterium bovis. J. Comp. Pathol. 119, $27-44$.
Cassidy, J.P., Bryson, D.G., Pollock, J.M., Evans, R.T., Forster, F., Neill, S.D., 1999. Lesions in cattle exposed to Mycobacterium bovis-inoculated cattle. J. Comp. Pathol. 121, 321-327.

Corner, L.A., 1994. Post mortem diagnosis of Mycobacterium bovis in cattle. Vet. Microbiol. 40, 53-63.

De Kantor, I.N., Roswurm, J.D., 1978. Mycobacteria isolated from nasal secretions of tuberculin test reactor cattle. Am. J. Vet. Res. 39, 1233-1238.

Doherty, M.L., Monaghan, L., Bassett, H.F., Quinn, P.J., 1995. Effect of recent injection of purified protein derivative on diagnostic tests for tuberculosis in cattle infected with Mycobacterium bovis. Res. Vet. Sci. 58, 217-221.

Dungworth, D.L., 1993. The respiratory system. In: Jubb, K.V.F., Kennedy, P.C., Palmer, N.C. (Eds.), Pathology of Domestic Animals. Academic Press, London, pp. 641-652.

Fifis, T., Rothel, J.S., Wood, P.R., 1994. Soluble Mycobacterium bovis protein antigens: studies on their purification and immunological evaluation. Vet. Microbiol. 40, 65-81.

Flynn, J.L., 2004. Immunology of tuberculosis and implications in vaccine development. Tuberculosis (Edinb.) 84, 93-101.

Flynn, J.L., Chan, J., 2001. Immunology of tuberculosis. Annu. Rev. Immunol. 19, 93-129.

Francis, J., 1947. Bovine Tuberculosis, Including a Contrast with Human Tuberculosis. Staples Press Ltd., London, pp. 86-87.

Garnier, T., Eiglmeier, K., Camus, J.C., Medina, N., Mansoor, H., Pryor, M., Duthoy, S., Grondin, S., Lacroix, C., Monsempe, C., Simon, S., Harris, B., Atkin, R., Doggett, J., Mayes, R., Keating, L., Wheeler, P.R., Parkhill, J., Barrell, B.G., Cole, S.T., Gordon, S.V., Hewinson, R.G., 2003. The complete genome sequence of Mycobacterium bovis. Proc. Natl. Acad. Sci. U.S.A. 100, 78777882.

Geluk, A., van Meijgaarden, K.E., Franken, K.L., Subronto, Y.W., Wieles, B., Arend, S.M., Sampaio, E.P., de Boer, T., Faber, W.R., Naafs, B., Ottenhoff, T.H., 2002. Identification and characterization of the ESAT-6 homologue of Mycobacterium leprae and T-cell cross-reactivity with Mycobacterium tuberculosis. Infect. Immunol. 70, 2544-2548.

Geluk, A., Van Meijgaarden, K.E., Franken, K.L., Wieles, B., Arend, S.M., Faber, W.R., Naafs, B., Ottenhoff, T.H., 2004. Immunological crossreactivity of the Mycobacterium leprae CFP-10 with its homologue in Mycobacterium tuberculosis. Scand. J. Immunol. 59, 66-70.

Gey Van Pittius, N.C., Gamieldien, J., Hide, W., Brown, G.D., Siezen, R.J., Beyers, A.D., 2001. The ESAT-6 gene cluster of Mycobacterium tuberculosis and other high G+C Gram-positive bacteria. Genome Biol. 2, 44-48.

Gey van Pittius, N.C., Warren, R.M., van Helden, P.D., 2002. ESAT6 and CFP-10: what is the diagnosis? Infect. Immunol. 70, 6509-6510 author reply 6511.

Gormley, E., Doyle, M.B., McGill, K., Costello, E., Good, M., Collins, J.D., 2004. The effect of the tuberculin test and the consequences of a delay in blood culture on the sensitivity of a gamma-interferon assay for the detection of Mycobacterium bovis infection in cattle. Vet. Immunol. Immunopathol. 102, 413-420.

Greenwald, R., Esfandiari, J., Lesellier, S., Houghton, R., Pollock, J., Aagaard, C., Andersen, P., Hewinson, R.G., Chambers, M., 
Lyashchenko, K., 2003. Improved serodetection of Mycobacterium bovis infection in badgers (Meles meles) using multiantigen test formats. Diagn. Microbiol. Infect. Dis. 46, 197203.

Griffin, J.F.T., Mackintosh, C.G., 2000. Tuberculosis in deer: perceptions, problems and progress. Vet. J. 160, 202-219.

Griffin, J.M., Dolan, L.A., 1995. The role of cattle-to-cattle transmission of Mycobacterium bovis in the epidemiology of tuberculosis in cattle in the Republic of Ireland: a review. Irish Vet. J. 48, 228-234.

Hall, M.R., Thoen, C.O., 1983. Lymphocyte immunostimulation responses following intravenous injection of Mycobacterium bovis PPD tuberculin in cattle experimentally exposed to $M$. bovis. Twenty-sixth Annual Proceedings of the American Association of Veterinary Laboratory Diagnositicians, pp. 52-61.

Kaufmann, S.H., 2001. How can immunology contribute to the control of tuberculosis? Nat. Rev. Immunol. 1, 20-30.

Koets, A.P., Rutten, V.P., de Boer, M., Bakker, D., Valentin-Weigand, P., van Eden, W., 2001. Differential changes in heat shock protein-, lipoarabinomannan, and purified protein derivativespecific immunoglobulin G1 and G2 isotype responses during bovine Mycobacterium avium subsp. paratuberculosis infection. Infect. Immunol. 69, 1492-1498.

Lepper, A.W.D., Pearson, C.W., 1973. The route of infection in tuberculous beef cattle. Aust. Vet. J. 49, 266-267.

Lepper, A.W., Pearson, C.W., Corner, L.A., 1977. Anergy to tuberculin in beef cattle. Aust. Vet. J. 53, 214-216.

Loudon, G.L., Roberts, R.M., 1967. Droplet expulsion from the respiratory tract. Am. Rev. Resp. Dis. 95, 435-442.

Loudon, G.L., Roberts, R.M., 1968. Singing and the dissemination of tuberculosis. Am. Rev. Resp. Dis. 98, 297-300.

Lyashchenko, K.P., Singh, M., Colangeli, R., Gennaro, M.L., 2000. A multi-antigen print immunoassay for the development of serological diagnosis of infectious diseases. J. Immunol. Meth. 242, 91-100.

Lyashchenko, K., Whelan, A.O., Greenwald, R., Pollock, J.M., Andersen, P., Hewinson, R.G., Vordermeier, H.M., 2004. Association of tuberculin-boosted antibody responses with pathology and cell-mediated immunity in cattle vaccinated with Mycobacterium bovis $\mathrm{BCG}$ and infected with $M$. bovis. Infect. Immunol. 72, 2462-2467.

Mackintosh, C.G., Griffin, J.F.T., 1994. Epidemiological aspects of deer tuberculosis research. In: Proceedings of the Deer Branch of the New Zealand Veterinary Association, vol. 10. pp. 222-228.

Mackintosh, C.G., Waldrup, K., Labes, R., Buchan, G., Griffin, F., 1995. Intra-tonsil inoculation: an experimental model for tuberculosis in deer. In: Griffin, F., deLisle, G. (Eds.), Otago Conference Series 3, Tuberculosis in Wildlife and Domestic Animals. University of Otago Press, Dunedin, New Zealand, pp. 121-122.

McIlroy, S.G., Neill, S.D., McCracken, R.M., 1986. Pulmonary lesions and Mycobacterium bovis excretion from the respiratory tract of tuberculin reacting cattle. Vet. Rec. 118, 718-721.

Monaghan, M.L., Doherty, M.L., Collins, J.D., Kazda, J.F., Quinn, P.J., 1994. The tuberculin test. Vet. Microbiol. 40, 111-124.
Neill, S.D., Hanna, J., Mackie, D.P., Bryson, T.G.D., 1992. Isolation of Mycobacterium bovis from the respiratory tracts of skin-test negative cattle. Vet. Rec. 131, 45-47.

Neill, S.D., Hanna, J., O’Brien, J.J., McCracken, R.M., 1988a. Excretion of Mycobacterium bovis by experimentally infected cattle. Vet. Rec. 123, 340-343.

Neill, S.D., Hanna, J., O’Brien, J.J., McCracken, R.M., 1989. Transmission of tuberculosis from experimentally infected cattle to in-contact calves. Vet. Rec. 124, 269-271.

Neill, S.D., O’Brien, J.J., Hanna, J., 1991. A mathematical model for Mycobacterium bovis excretion from tuberculous cattle. Vet. Microbiol. 28, 103-109.

Neill, S.D., O’Brien, J.J., McCracken, R.M., 1988b. Mycobacterium bovis in the anterior respiratory tracts in heads of tuberculinreacting cattle. Vet. Rec. 122, 184-186.

Neill, S.D., Pollock, J.M., Bryson, D.B., Hanna, J., 1994. Pathogenesis of Mycobacterium bovis infection in cattle. Vet. Microbiol. 40, 41-52.

North, R.J., Jung, Y.J., 2004. Immunity to tuberculosis. Annu. Rev. Immunol. 22, 599-623.

O’Brien, D.J., Fitzgerald, S.D., Lyon, T.J., Butler, K.L., Fierke, J.S., Clarke, K.R., Schmitt, S.M., Cooley, T.M., Derry, D.E., 2001. Tuberculous lesions in free-ranging white-tailed deer in Michigan. J. Wild. Dis. 37, 608-613.

Palmer, M.V., Waters, W.R., Thacker, T.C., Stoffregen, W.C., Thomsen, B.V., 2006. Experimental infection of reindeer (Rangifer tarandus) with Mycobacterium bovis. J Vet. Diagn. Invest. $18,51-59$.

Palmer, M.V., Waters, W.R., Whipple, D.L., 2002a. Aerosol delivery of virulent Mycobacterium bovis to cattle. Tuberculosis 82, 275282.

Palmer, M.V., Waters, W.R., Whipple, D.L., 2003. Aerosol exposure of white-tailed deer (Odocoileus virginianus) to Mycobacterium bovis. J. Wild. Dis. 39, 817-823.

Palmer, M.V., Waters, W.R., Whipple, D.L., 2004a. Investigation of the transmission of Mycobacterium bovis from deer to cattle through indirect contact. Am. J. Vet. Res. 65, 1483-1489.

Palmer, M.V., Waters, W.R., Whipple, D.L., 2004b. Shared feed as a means of deer to deer transmission of Mycobacterium bovis. J. Wild. Dis. 40, 87-91.

Palmer, M.V., Whipple, D.L., Butler, K.L., Fitzgerald, S.D., Bruning-Fann, C.S., Schmitt, S.M., 2002b. Tonsillar lesions in whitetailed deer (Odocoileus virginianus) naturally infected with Mycobacterium bovis. Vet. Rec. 151, 149-150.

Palmer, M.V., Whipple, D.L., Olsen, S.C., 1999a. Development of a model of natural infection with Mycobacterium bovis in whitetailed deer. J. Wild. Dis. 35, 450-457.

Palmer, M.V., Whipple, D.L., Payeur, J.B., Alt, D.P., Esch, K.J., Bruning-Fann, C.S., Kaneene, J.B., 2000. Naturally occurring tuberculosis in white-tailed deer. J. Am. Vet. Assoc. 216, 19211924.

Palmer, M.V., Whipple, D.L., Rhyan, J.C., Bolin, C.A., Saari, D.A., 1999b. Granuloma development in cattle after intratonsilar inoculation with Mycobacterium bovis. Am. J. Vet. Res. 60, 310-315.

Palmer, M.V., Whipple, D.L., Waters, W.R., 2001. Experimental deer to deer transmission of Mycobacterium bovis. Am. J. Vet. Res. 62, 692-696. 
Phillips, C.J.C., Foster, C.R.W., Morris, P.A., Teverson, R., 2003. The transmission of Mycobacterium bovis infection to cattle. Res. Vet. Sci. 74, 1-15.

Plackett, P., Ripper, J., Corner, L.A., Small, K., de Witte, K., Melville, L., Hides, S., Wood, P.R., 1989. An ELISA for the detection of anergic tuberculous cattle. Aust. Vet. J. 66, 15-19.

Pollock, J.M., Andersen, P., 1997. The potential of the ESAT-6 antigen secreted by virulent mycobacteria for specific diagnosis of tuberculosis. J. Infect. Dis. 175, 1251-1254.

Pollock, J.M., Girvin, R.M., Lightbody, K.A., Clements, R.A., Neill, S.D., Buddle, B.M., Andersen, P., 2000. Assessment of defined antigens for the diagnosis of bovine tuberculosis in skin testreactor cattle. Vet. Rec. 146, 659-665.

Pollock, J.M., McNair, J., Bassett, H., Cassidy, J.P., Costello, E., Aggerbeck, H., Rosenkrands, I., Andersen, P., 2003. Specific delayed-type hypersensitivity responses to ESAT-6 identify tuberculosis-infected cattle. J. Clin. Microbiol. 41, 1856-1860.

Pollock, J.M., McNair, J., Welsh, M.D., Girvin, R.M., Kennedy, H.E., Mackie, D.P., Neill, S.D., 2001. Immune responses in bovine tuberculosis. Tuberculosis (Edinb.) 81, 103-107.

Radunz, B.L., Lepper, A.W.D., 1985. Suppression of skin reactivity to bovine tuberculin in repeat tests. Aust. Vet. J. 62, 191-194.

Ramsay, A.D., 1992. Palatine tonsil. In: McGee, J.O’D., Isaacson, P.G., Wright, N.A. (Eds.), Oxford Textbook of Pathology, 2a. Oxford University Press, Oxford, pp. 1122-1123.

Renshaw, P.S., Panagiotidou, P., Whelan, A., Gordon, S.V., Hewinson, R.G., Williamson, R.A., Carr, M.D., 2002. Conclusive evidence that the major T-cell antigens of the Mycobacterium tuberculosis complex ESAT-6 and CFP-10 form a tight, 1: 1 complex and characterization of the structural properties of ESAT-6, CFP-10, and the ESAT-6:CFP-10 complex. Implications for pathogenesis and virulence. J. Biol. Chem. 277, 21598-21603.

Rhodes, S.G., Gavier-Widen, D., Buddle, B.M., Whelan, A.O., Singh, M., Hewinson, R.G., Vordermeier, H.M., 2000. Antigen specificity in experimental bovine tuberculosis. Infect. Immunol. 68, 2573-2578.

Robinson, R.C., Phillips, P.H., Stevens, G., Storm, P.A., 1989. An outbreak of Mycobacterium bovis infection in fallow deer (Dama dama). Aust. Vet. J. 66, 195-197.

Rothel, J.S., Jones, S.L., Corner, L.A., Cox, J.C., Wood, P.R., 1992. The gamma-interferon assay for diagnosis of bovine tuberculosis in cattle: conditions affecting the production of gammainterferon in whole blood culture. Aust. Vet. J. 69, 1-4.

Ryan, T.J., Buddle, B.M., de Lisle, G.W., 2000. An evaluation of the gamma interferon test for detecting bovine tuberculosis in cattle 8 to 28 days after tuberculin skin testing. Res. Vet. Sci. 69, 57-61.

Samuelson, J., von Lichtenberg, F., 1994. Infectious diseases. In: Robbins, S.L., Kumar, V. (Eds.), Robbins Pathologic Basis of Disease. 5th ed. W.B. Saunders Co., Philadelphia, pp. 324-325.

Sigurdson, J., 1945. Studies on the risk of infection with bovine tuberculosis to the rural population. In: Acta Tuberculosea Scandinavica Supplementum XV, Munskgaard, Copenhagen, pp. 26-40.

Stamp, J.T., 1944. A review of the pathogenesis and pathology of bovine tuberculosis with special reference to practical problems. Vet. Rec. 56, 443-446.
Thom, J., Morgan, J.H., Hope, J.C., Villarreal-Ramos, B., Martin, M., Howard, C.J., 2004. The effect of repeated tuberculin skin testing of cattle on immune responses and disease following experimental infection with Mycobacterium bovis. Vet. Immunol. Immunopathol. 102, 399-412.

Vordermeier, H.M., Cockle, P.C., Whelan, A., Rhodes, S., Palmer, N., Bakker, D., Hewinson, R.G., 1999. Development of diagnostic reagents to differentiate between Mycobacterium bovis BCG vaccination and $M$. bovis infection in cattle. Clin. Diagn. Lab. Immunol. 6, 675-682.

Vordermeier, H.M., Simsova, M., Wilkinson, K.A., Wilkinson, R.J., Hewinson, R.G., Sebo, P., Leclerc, C., 2004. Recognition of mycobacterial antigens delivered by genetically detoxified Bordetella pertussis adenylate cyclase by $\mathrm{T}$ cells from cattle with bovine tuberculosis. Infect. Immunol. 72, 6255-6261.

Vordermeier, H.M., Whelan, A., Cockle, P.J., Farrant, L., Palmer, N., Hewinson, R.G., 2001. Use of synthetic peptides derived from the antigens ESAT- 6 and CFP-10 for differential diagnosis of bovine tuberculosis in cattle. Clin. Diagn. Lab. Immunol. 8, 571-578.

Waters, W.R., Miller, J.M., Palmer, M.V., Stabel, J.R., Jones, D.E., Koistinen, K.A., Steadham, E.M., Hamilton, M.J., Davis, W.C., Bannantine, J.P., 2003. Early induction of a humoral and cellular immune response during experimental Mycobacterium avium subsp. paratuberculosis infection of calves. Infect. Immunol. 71, 5130-5138.

Waters, W.R., Nonnecke, B.J., Palmer, M.V., Robbe-Austermann, S., Bannantine, J.P., Stabel, J.R., Whipple, D.L., Payeur, J.B., Estes, D.M., Pitzer, J.E., Minion, F.C., 2004a. Use of recombinant ESAT-6:CFP-10 fusion protein for differentiation of infections of cattle by Mycobacterium bovis and by M. avium subsp. avium and M. avium subsp. paratuberculosis. Clin. Diag. Lab. Immunol. 11, 729-735.

Waters, W.R., Palmer, M.V., Bannantine, J.P., Whipple, D.L., Greenwald, R., Esfandiari, J., Andersen, P., McNair, J., Pollock, J.M., Lyashchenko, K.P., 2004b. Antigen recognition by serum antibodies in white-tailed deer (Odocoileus virginianus) experimentally infected with Mycobacterium bovis. Clin. Diagn. Lab. Immunol. 11, 849-855.

Wells, W.F., Ratcliffe, H.I., Crumb, C., 1948. On the mechanisms of droplet nuclei infection. II. Quantitative experimental airborne tuberculosis in rabbits. Am. J. Hyg. 47, 11-28.

Whipple, D.L., Palmer, M.V., Slaughter, R.E., Jones, S.L., 2001. Comparison of purified protein derivatives and effect of skin testing on results of a commercial gamma interferon assay for diagnosis of tuberculosis in cattle. Am. J. Vet. Res. 13, 117122.

Whiting, T.L., Tessaro, S.V., 1994. An abattoir study of tuberculosis in a herd of farmed elk. Can. Vet. J. 35, 497-502.

Wood, P.R., Corner, L.A., Rothel, J.S., Ripper, J.L., Fifis, T., McCormick, B.S., Francis, B., Melville, L., Small, K., de Witte, K., Tolson, J., Ryan, T.J., deLisle, G.W., Cox, J.C., Jones, S.L., 1992. A field evaluation of serological and cellular diagnostic tests for bovine tuberculosis. Vet. Microbiol. 31, 71-79.

Wood, P.R., Jones, S.L., 2001. BOVIGAM ${ }^{\mathrm{TM}}$ : an in vitro cellular diagnostic test for bovine tuberculosis. Tuberculosis $81,147-$ 155. 